\title{
High Temperature Stability and Thermal Cycling Life of Plasma Sprayed Nanostructured Thermal Barrier Coating with Low Impurity Content
}

\author{
Tao Yuan, a, Qing He 1, b, YuFen Lv', c, Han Zou, d \\ ${ }^{1}$ Chinese Academy of Agricultural Mechanization Sciences,
}

No.1 Beishatan Deshengmen wai, Chaoyang District, Beijing, China, 100083

${ }^{2}$ Beijing Jinlunkuntian Special Machine Co., Ltd,

No.1 Beishatan Deshengmen wai, Chaoyang District, Beijing, China, 100083

aYuantao-2320@163.com, bheqing68@gmail.com, Ivyufen7875@dingtalk.com, ${ }^{\mathrm{d} 13521368030 @ 126 . c o m}$

\begin{abstract}
Keywords: Nanostructured coating; Thermal barrier coating; Air plasma spray; High temperature stability; Thermal cycling life

Abstract. Nanostructured 8YSZ(6 8 wt.\% Y2O3 partially stabilized zirconia) thermal barrier coatings(TBCs) have been proved which can improve the thermal conductivity and durability compare to conventional coatings. There are still concerns in the engineer and scientific community about the stability of nanostructured 8YSZ coatings at high temperatures. In this work, modified nano-8YSZ coating with low impurity content and optimized microstructure was prepared by atmospheric plasma spraying. The effects of annealing on the nano-8YSZ coating were investigated, and thermal cycling life under high temperature gradient was analyzed. The result revealed that the modified nano-8YSZ coating exhibited low content of monoclinic phase after annealed 100h at $1400^{\circ} \mathrm{C}$, and extra low linear contraction through the thickness of the coatings, about $68 \%$ lower than that for the common nano-8YSZ coating. The modified nano-TBC exhibited a thermal cycling lifetime of 1429 cycles, whereas failure of the common nano-8YSZ coating TBC occurred within 800 cycles. Improved high temperature stability could be the main reason for longer thermal cycling life of the modified nano-TBC.
\end{abstract}

\section{Introduction}

Thermal barrier coatings(TBCs) have been widely used in the surface of high pressure turbine blades and vanes in aero-engines and land-based gas turbines ${ }^{[1,2]}$. TBCs usually comprise a metallic bond coat(MCrAlY or NiPtAl) for high temperature oxidation and corrosion resistance, also improve adhesion of top coat with matrix alloy. The common top coating material is 6 8wt.\% Yttria Partially Stabilized Zirconia(8YSZ) ${ }^{[3][4]}$. At present, traditional 8 YSZ coating have some limits used in modern advanced aero-engines, such as limit of heat insulation effection, high temperature phase stability and sintering resistance ${ }^{[5 \sim 7]}$. Different approaches have been employed to achieve the goal for enhance the performance of traditional 8YSZ TBCs, such as decrease the content of impurities in coating and prepare the nanostructured coating by thermal spraying with agglomerated nano-8YSZ powders.

Nanostructure 8YSZ coating can decrease the thermal conductivity and improve the durability compare to convention coating of the same composition has been approved, this contribute to the fine grain size, high volume of superfine porous, semi-molten particles and nonmolten particles ${ }^{[15-17]}$.

Lima and Marple ${ }^{[18,19]}$ obtained a highly sintering-resistant nanostructure 8YSZ coating with bimodal structure consisted of fully molten and semimolten particles, and size of nonmolten nanoparticle areas is important for performance of the coating, sometimes is occupied an area of $30-35 \%$.

Some literatures ${ }^{[12-14]}$ reported the influencing factors for phase stability and sintering rates of zirconia based materials, dopants content, dopants distribution, impurity content, grain size, grain boundary phase etc., all of above combined influence the high temperature stability of zirconia based materials. S. Paul ${ }^{[8]}$ compared the Y-PSZ coatings with various impurity content, low impurity 
content effects a significant reduction in the sintering rates and high temperature phase stability, and also exhibited lower stiffness and thermal conductivity increased rate for coating with low impurity coating under prolonged heattreatment. $\mathrm{Basu}^{[20]}$ reviewed toughening of yttria-stabilised tetragonal zirconia ceramics, formation of aluminosilicate or silica rich glassy grain boundary phase is promoted, respectively by the presence of higher $\mathrm{Al}_{2} \mathrm{O}_{3}$ or $\mathrm{SiO}_{2}$ contents in the starting powders. Strong yttrium segregation at grain boundaries and grain triple junctions caused tetragonal $(t) \rightarrow \operatorname{monoclinic}(m)$ phase transformation aggravated and sintering rates increased sharply. For TBCs, accelerate phase transformation and sintering cause premature failure.

It affirmed that decrease grain size can increase stability of $t-\mathrm{ZrO}_{2}$ and lower impurity can improve high temperature sintering resistance and phase stability of Y-PSZ, all of this can improve durability of thermal barrier coatings ${ }^{[8,15,18,19]}$, only risk is fracture toughness increase with grain size and impurity that reported of Y-PSZ ceramics ${ }^{[8]}$. However, considering the erosion is an important factor for failure mechanism of Y-PSZ TBCs, erosion caused near surface cracking and layer-by-layer uncovering of APS-TBCs ${ }^{[21,22]}$. If nanostructure Y-PSZ coatings with high volume of nonmolten nanoparticle areas, will decrease the erosion performance and bond strength of the APS-TBCs, and maybe decrease the thermal cycle life of coating in complex service condition.

In the current work, Y-PSZ coatings were deposited by air plasma spraying. Two types of nano agglomerated powder feedstock were used, with high impurity and low impurity content. The influence of the composition and powder type on the high temperature stability of coatings with low volume of semi-molten was investigated.

\section{Experimental Procedures}

The top coatings were produced from two different nano-agglomerated powders, one is for commercially used, and other is developed by CAAMS. Powder composition can be found in table 1 . The apparent density of JLN sprayed powder was $1.97 \mathrm{~g} / \mathrm{cm}^{3}$ and NY2 powder was $1.96 \mathrm{~g} / \mathrm{cm}^{3}$, particle size range was 37 61 $\mu \mathrm{m}$ and 37 90 $\mu \mathrm{m}$ respectively.

The powder was deposited onto a stainless steel by atmosphere plasma spray(APS), the spraying power was $45 \mathrm{KW}$, spray distance was $80 \mathrm{~mm}$ and powder feed rate was $20 \mathrm{~g} / \mathrm{min}$. Dimension of nanostructured coating for high temperature stability test was $\Phi 10 \times(0.5 \sim 1) \mathrm{mm}$, and the sample for dilatometer test was $\Phi 6 \times 2 \mathrm{~mm}$.

The high temperature heattreatment was conduced in a box furnace with $\mathrm{MoSi}_{2}$ heating element, and aluminde crucible used for sample container. Powder for phase stability analyzed was sampling from the center of the crucible for decreased the effect of aluminde crucible, and sintered 50h, 100h, $200 \mathrm{~h}$ receptivity. Coatings in high temperature heattreatment were separated by the initial sprayed powder from crucible, avoided high temperature interdiffusion with 7YSZ coatings and aluminde crucible. Coatings were sintered $100 \mathrm{~h}$ at $1200^{\circ} \mathrm{C}, 1300^{\circ} \mathrm{C}$ and $1400^{\circ} \mathrm{C}$ receptivity.

X-Ray Diffraction (XRD) patterns were obtained with a Rigaku DMAX-RB X-Ray Diffractometer with a scan speed $1 \%$ min. Raman spectrum were tested by a Renishaw RM2000 Microscopic Confocal Raman Spectrometer with Raman shift from 100 to $4000 \mathrm{~cm}^{-1}$, spectrum resolution of $1 \mathrm{~cm}^{-1}$ and laser wavelengh of $514.5 \mathrm{~nm}$ (argon ion). Microstructural observations was carried out on a Hitachi S3400N SEM and Zeiss 55VP FE-SEM. Netzsch DIL 402C thermal dilatometer used to obtain the dimensional changes through coating thickness at $1260^{\circ} \mathrm{C}$ and 10 hours thermal retardation, and analyzed high temperature sintering resistance by the dimensional changes under the stage of thermal retardation. The characterizations of the as-sprayed and heat-treated coatings were performed using the JEOL JEM-2010 TEM instrument.

\section{Results and discussion}

Nano 7YSZ powders synthesized by the method of chemical coprecipitation, micrograph of nano powder before JLN agglomerated as shown in Fig.1, the particle size of original powder was 10 to 20nm distinguished from FE-SEM image. If considered the self-agglomerate effect, actual average 
powder size less than 10nm. JLN sprayed powder have low impurity content(Table.1), the powder processed by spray dried and plasma densification with a rapidly sintered shell in the surface layer, and some nano-agglomerated with different density in the sintered shell(Fig.2(a), (b), (c)). This microstructural design for sprayed powder can increase the intensity and thermal conductivity of global agglomerated particles, increased the deposition efficiency and decreased the difficulty for nano powders melted at the process of plasma spraying. $\mathrm{NY} 2$ powder with high $\mathrm{Al}_{2} \mathrm{O}_{3}, \mathrm{SiO}_{2}$, etc. impurity content and with a hollow or dense microstructure(Fig.2 (d), (e)), this powder produced by special heattreatment process, surface of the global particle retained nano scale(Fig.2(f)).

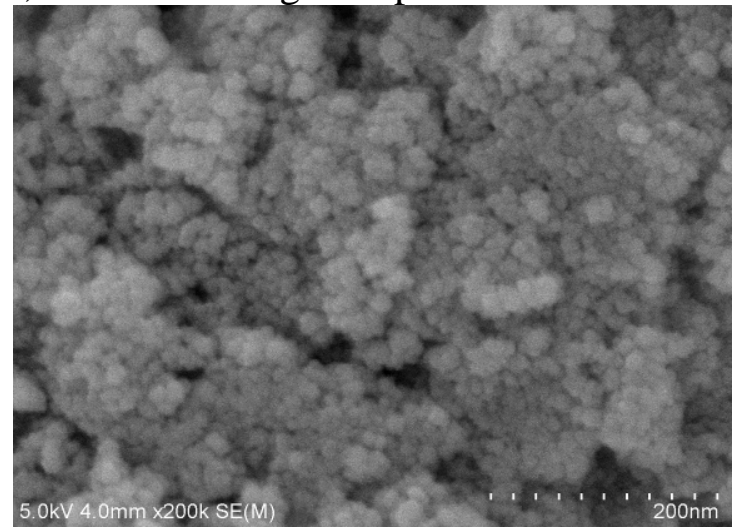

Fig.1 Microstructure of the original nano particles (before agglomerated)

Table.1 Chemical composition of initial sprayed powders

\begin{tabular}{cccccccccc}
\hline Powders & $\mathrm{ZrO}_{2}$ & $\mathrm{HfO}_{2}$ & $\mathrm{Y}_{2} \mathrm{O}_{3}$ & $\mathrm{Al}_{2} \mathrm{O}_{3}$ & $\mathrm{SiO}_{2}$ & $\mathrm{Fe}_{2} \mathrm{O}_{3}$ & $\mathrm{CaO}$ & $\mathrm{MgO}$ & $\mathrm{Cl}^{-1}$ \\
\hline JLN & Bal & $<2$ & 7.55 & $<0.01$ & $<0.01$ & $<0.01$ & $<0.005$ & $<0.01$ & 0.026 \\
$\mathrm{NY} 2$ & $\mathrm{Bal}$ & $<2$ & 7.01 & 0.1 & 0.02 & 0.01 & 0.01 & 0.01 & 0.038 \\
\hline
\end{tabular}
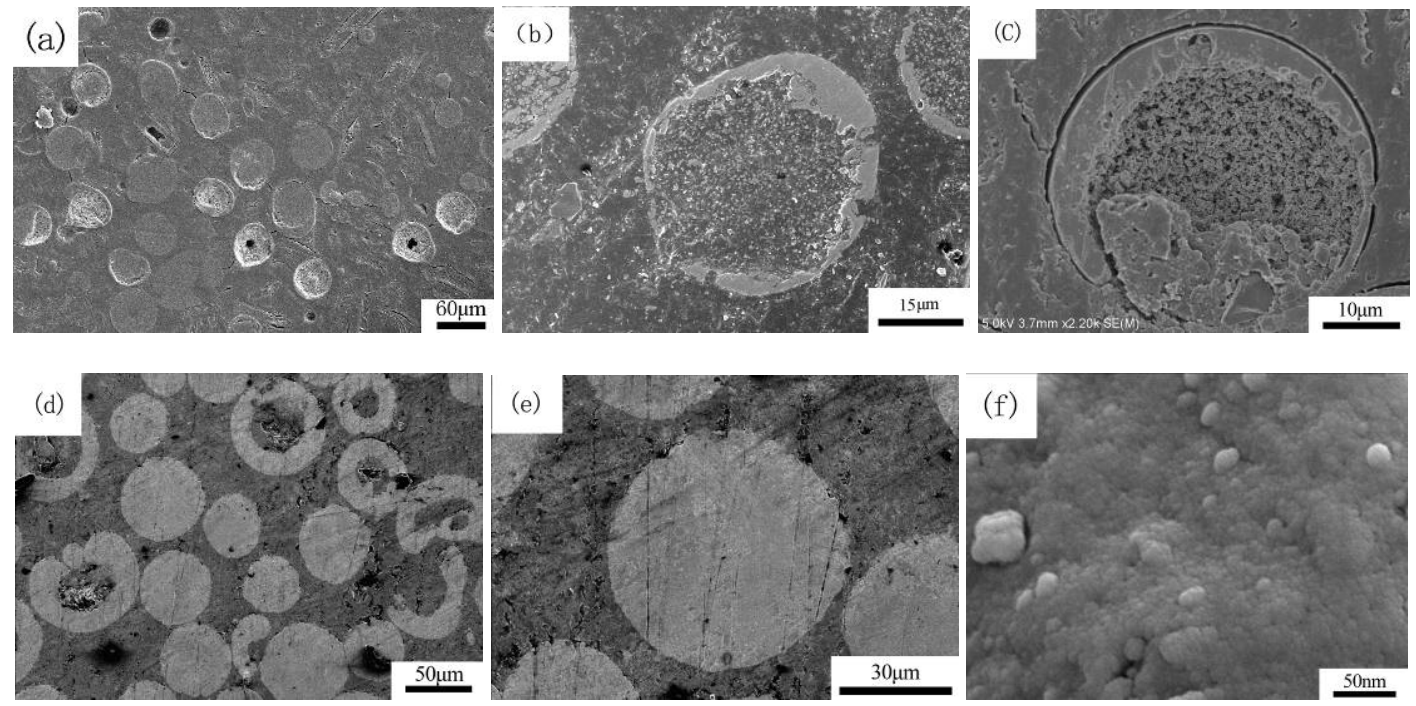

Fig.2 Cross-section micrographs and surface micrographs of initial sprayed powder. (a), (b) and (c): cross-section of JLN; (d), (e): cross-section of NY2; (f): surface micrograph of NY2.

Yttrium interdiffusion at the grain boundary caused high temperature phase transform of 7YSZ material, so phase stability of raw powder for plasma spray can affect the coating at a certain extent. JLN and NY2 sprayed powders were all the single metastable tetragonal phase from split phenomenon of $t(004)$ and $t(400)$ diffraction peaks(Fig.3). After JLN powder annealing 50h at 
$1400^{\circ} \mathrm{C}, m(111)$ and $m(11 \overline{2})$ peaks appeared and the ratio of intensity of $m(11 \overline{1})$ peak and $t, c(111)$ peak increased with prolonged annealing time. For NY2 powder, $m(110)$ and $m(011)$ peaks clearly appeared after $100 \mathrm{~h}$ annealing, intensity of main peak for monoclinic phase and the ratio of main peak for monoclinic and tetragonal phase is more higher than JLN powder. Quantitative determination of each phase was calculated following a method similar to that described by Miller et al. ${ }^{[23]}$ Content of tetragonal prime $t$ ' phases calculated together with tetragonal $t$ phase, The equations used were as follows:

$$
\begin{aligned}
& \frac{M_{m}}{M_{c, t, t^{\prime}}}=0.82 \frac{I_{m}(11 \overline{1})+I_{m}(111)}{I_{c, t}(111)} . \\
& \frac{M_{c}}{M_{t, t^{\prime}}}=0.88 \frac{I_{c}(400)}{I_{t, t^{\prime}}(400)+I_{t, t^{\prime}}(004)} .
\end{aligned}
$$

Where $M_{m}, M_{t}, M_{t}$, and $M_{c}$ are the molar fractions of the monoclinic, tetragonal, and cubic phases, and I represents the intensity of a given peak.
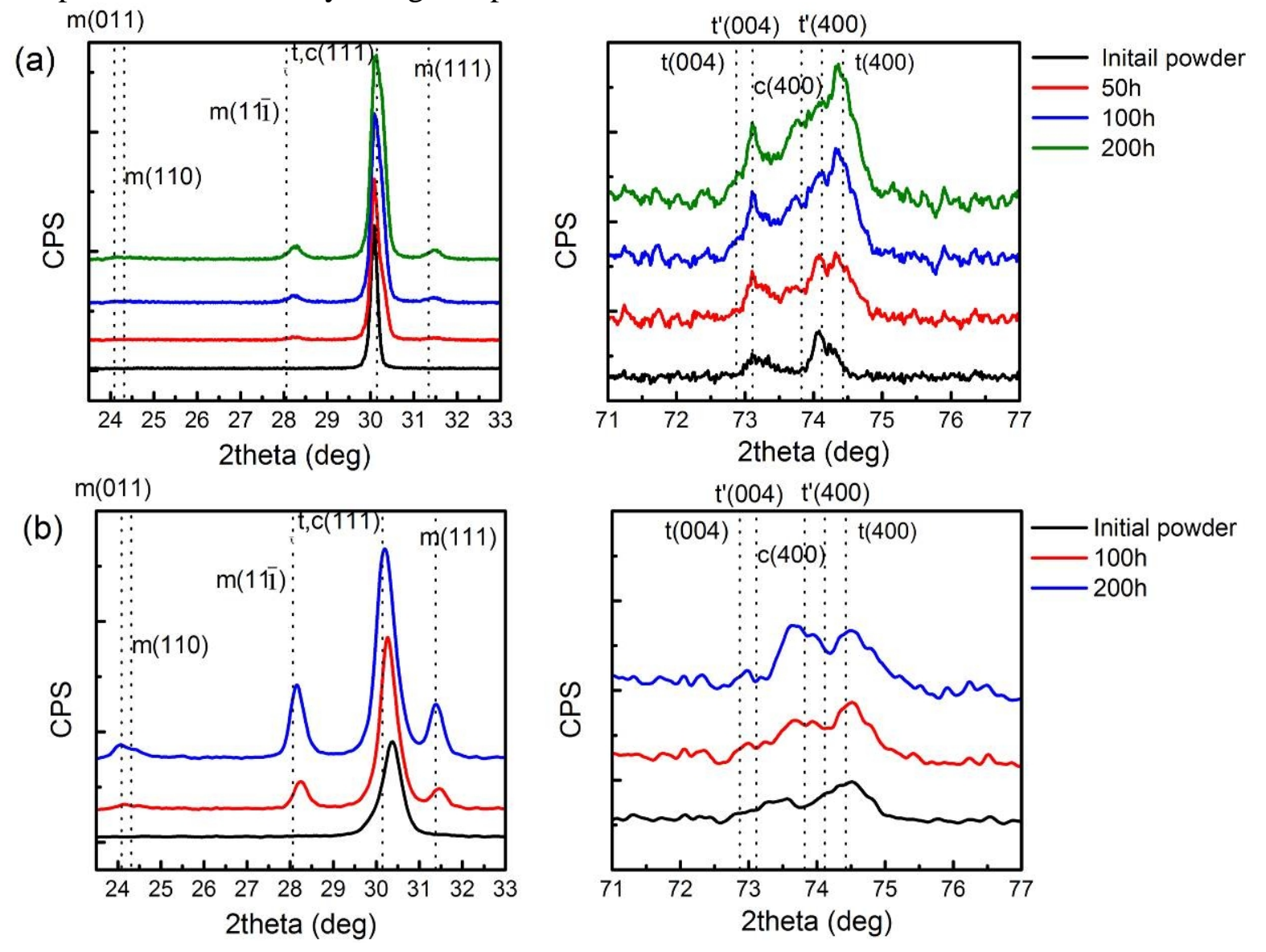

Fig. 3 Low angle and high angle XRD patterns for powders before and after $1400^{\circ} \mathrm{C}$ heattreatment.

(a): JLN powder, (b) NY2 powder.

The tetragonal to monoclinic transformation is accompanied by an approximate $3 \%$ volume change that causes stress in the coating and can lead to spallation. It is well-known that metastable t' phase does not directly transform to the monoclinic state upon cooling and exhibit longer thermal cycle life. Plasma spray 7YSZ thermal barrier coatings generally produced for a single tetragonal prime t' phase considering the best integrative properties, and other key demand for coating is long time hold facility for tetragonal prime t' phase in formidable service condition. Fig.4 is the mole percent of phase content for powders annealing $100 \mathrm{~h}, 200 \mathrm{~h}$ at $1400^{\circ} \mathrm{C}$, JLN powder with low impurity content 
exhibited more excellent high temperature phase stability, mole percent of monoclinic phase was more less than the NY2 powder at the same annealing time, indicated that decreased the impurity content can improve high temperature stability for 7YSZ material.

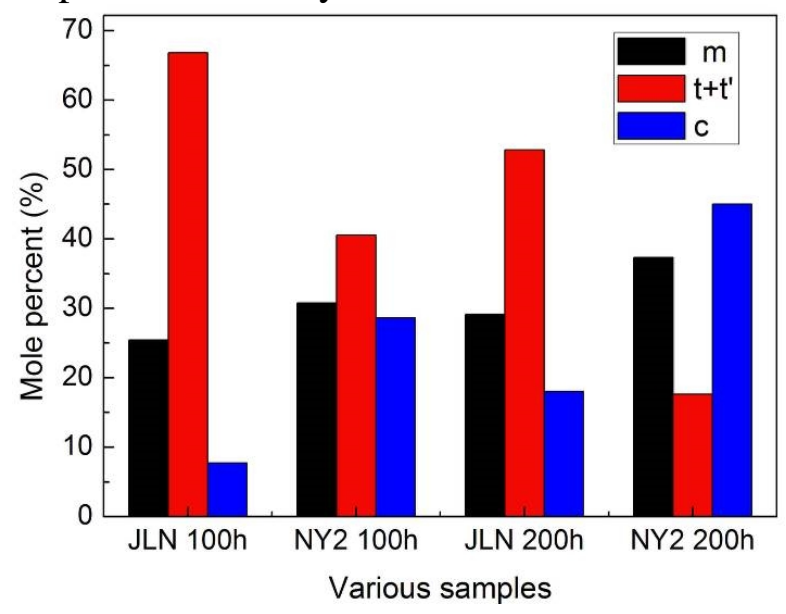

Fig.4 The change in mol\% of the phase content for JLN and NY2 powders annealed at $1400^{\circ} \mathrm{C}$

The coatings produced by Plasma Spray did not contain monoclinic phase(Fig.5(a)), after 100h annealing at $1400^{\circ} \mathrm{C}$, phase transform tendency of the coatings were the same of the powders from low angle XRD pattern. NY2 coating contained more monoclinic phase, illuminated the impurity content in sprayed powder can effect the high temperature phase stability of coating. Raman spectrum also used to obtain the phase constitution of the coatings after $100 \mathrm{~h}$ annealing at $1400^{\circ} \mathrm{C}(\mathrm{Fig} .5(\mathrm{~b}))$, the measure spot size was $5 \mu \mathrm{m}$, and used to obtain the phase constitution of microzone in the coating surface. In a random area, NY2 coating presented high level monoclinic phase content, intensity of main peak of monoclinic phase was higher than the cubic and tetragonal phase. However, JLN coating retained a great number of tetragonal phases after annealing $100 \mathrm{~h}$ at $1400^{\circ} \mathrm{C}$. Grain size of the coating was less than $5 \mu \mathrm{m}($ Fig.6(h)), so interdiffusion rate of NY2 coating was higher the JLN coating with low impurity in a $5 \mu \mathrm{m}$ diameter random area at high temperature annealed condition. Impurities affect on grain boundary of coating maybe an important factor for high temperature phase stability of 7YSZ nanostructure coating.
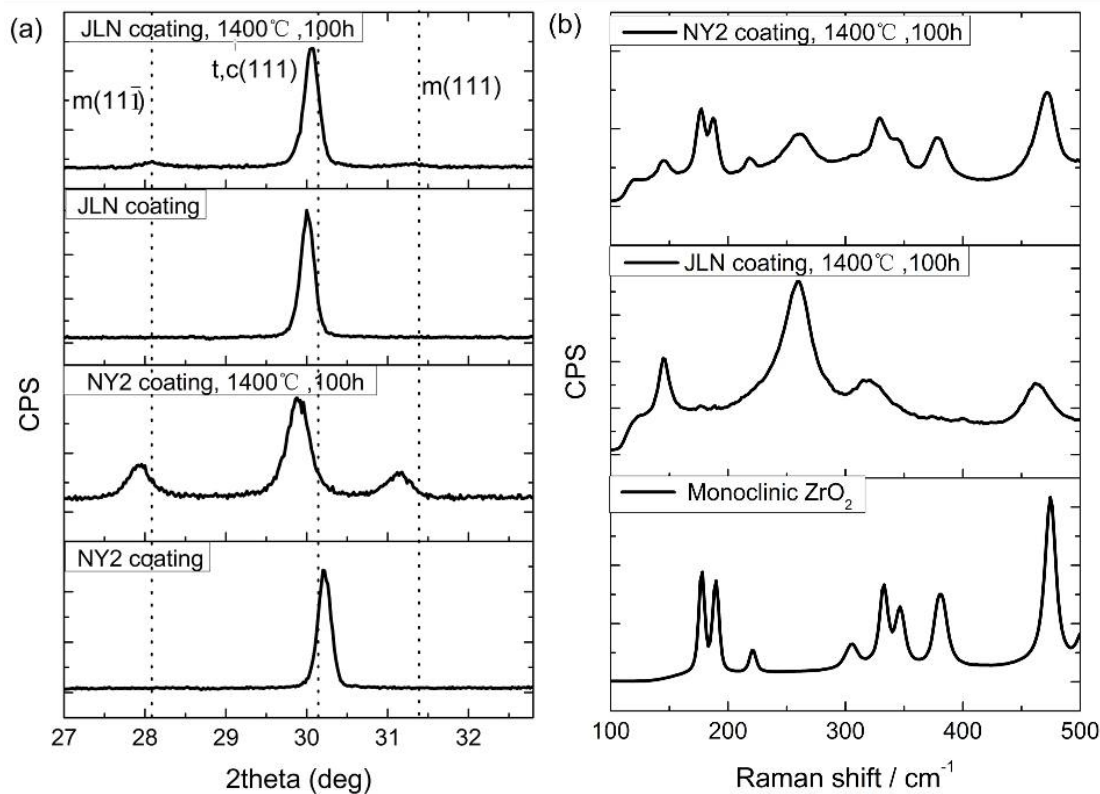

Fig.5 Low angle XRD patterns for coatings before and after annealed $100 \mathrm{~h}$ at $1400^{\circ} \mathrm{C}$ and Raman spectrum for coatings after annealed $100 \mathrm{~h}$ at $1400^{\circ} \mathrm{C}$. (a): XRD, (b) Raman. 
Micrograph of surface, cross-section and fracture of coatings was obtained by SEM and FE-SEM, contained as-sprayed coatings and coatings annealing $100 \mathrm{~h}$ at $1200^{\circ} \mathrm{C}, 1300^{\circ} \mathrm{C}, 1400^{\circ} \mathrm{C}$ respectively. For improve the bond strength and erosion resistance of the coatings, as-sprayed coatings with low volume of non-molten particles as shown in Fig.6 and Fig.7. Surface micrograph of the coatings is shown in Fig.6, different characteristics of pores, nonmolten particles, semi-molten particles, splats and cracks present in the coating surface. Size of nonmolten particle(top right corner of each picture in Fig.6) and grain size are increased with increasing annealing temperature at same heattreatment time. Surface layers were exfoliated in the coating surface after annealing at different temperature(Fig.6(a) (d)), and some larger pores than the as-sprayed coating appeared after annealing(Fig.6(f) and Fig6.(h)). Amount of nonmolten particles in JLN coating was higher than NY2 coating, related with the microstructure of the sprayed powder. Size of nonmolten particle was finer in the surface of JLN coating, this phenomenon maybe caused by the microstructure and density of global particle of initial sprayed powder, dense particle obtained excellent melt effect and partial nonmolten particles sintered induce grain size growth in plasma spray process. Growth rate of nonmolten particle was increased with annealing temperature, and average particle size of nonmolten nano particles of NY2 coating was higher than JLN coating after annealing at different temperature, microstructure of nonmolten particles in the surface of NY2 coating annealed $100 \mathrm{~h}$ at $1200^{\circ} \mathrm{C}$ was close to JLN coating annealed $100 \mathrm{~h}$ at $1300^{\circ} \mathrm{C}$, impurity content and microstructure of initial spayed powder maybe caused this result. AS mentioned, some pores also existd in the unmolten particles, and the size of pores after annealing was larger than as-sprayed coating, this phenomena caused by nano particles growth up and superfine pores combined. Unmolten particles obviously accelerated sintered during annealed temperature at $1400^{\circ} \mathrm{C}$, and size of some particles of nonmolten in NY2 coating was more than $1 \mu \mathrm{m}$.
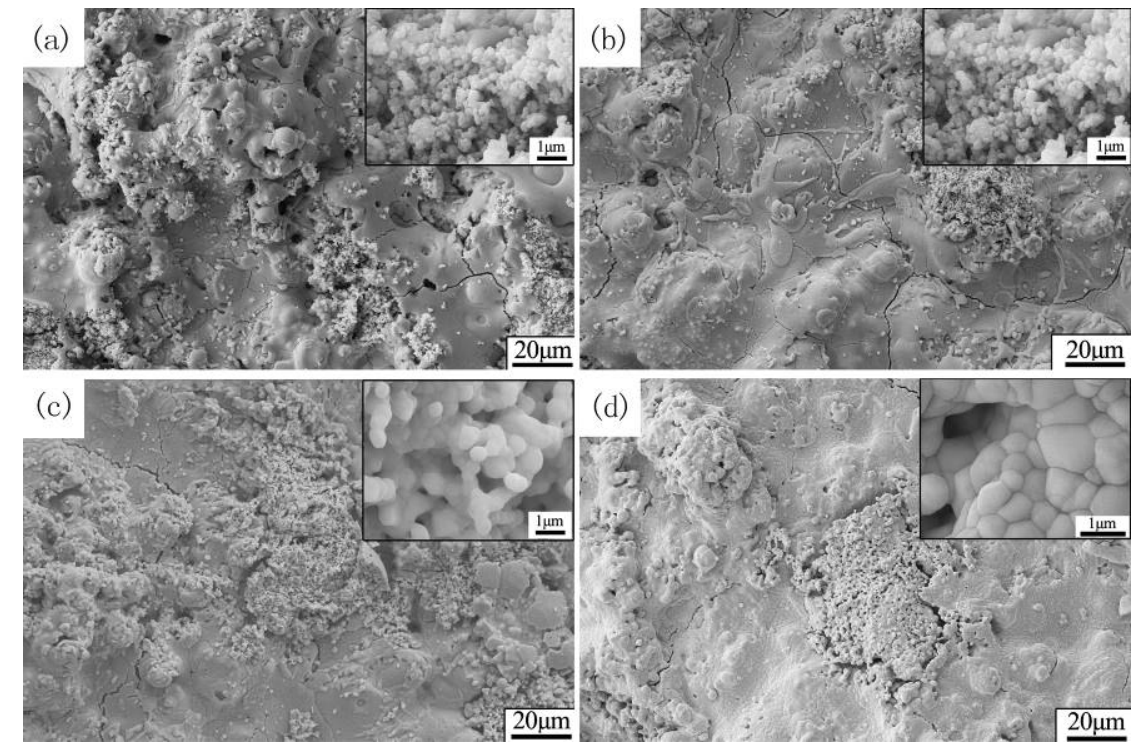

Fig.6 Surface morphology of JLN and NY2 coatings. (a): JLN(as-sprayed); (b): JLN(1200 $\left.{ }^{\circ} \mathrm{C}, 100 \mathrm{~h}\right)$; (c): JLN $\left(1300^{\circ} \mathrm{C}, 100 \mathrm{~h}\right)$; (d): JLN $\left(1400^{\circ} \mathrm{C}, 100 \mathrm{~h}\right)$; (e): NY2(as-sprayed); (f): $\mathrm{NY} 2\left(1200^{\circ} \mathrm{C}, 100 \mathrm{~h}\right)$;

(g): NY2(1300 $\left.{ }^{\circ}, 100 h\right) ;(h): ~ N Y 2\left(1400^{\circ} \mathrm{C}, 100 \mathrm{~h}\right)$ 

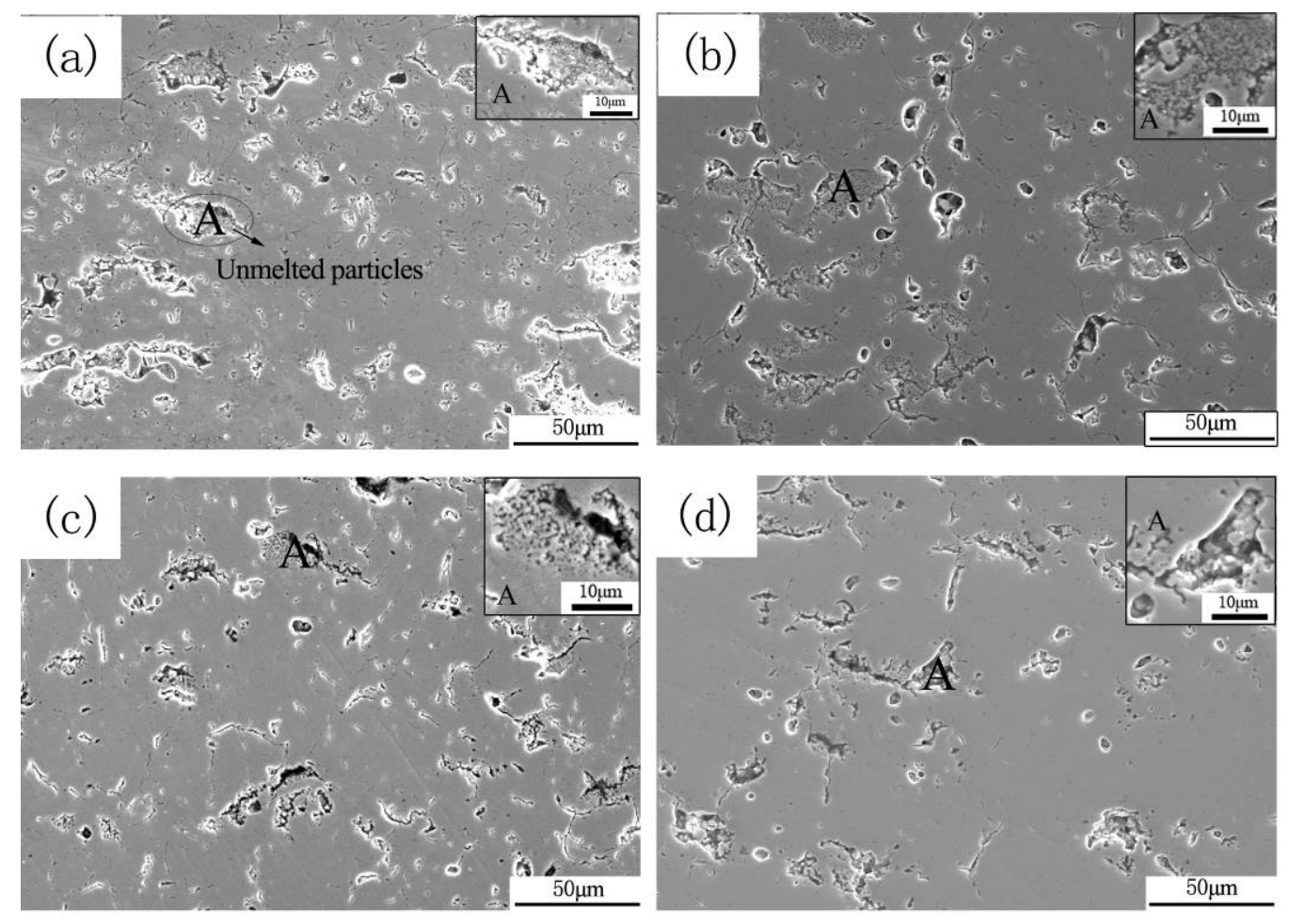

Fig.7 Cross-section micrograph of JLN and NY2 coatings. (a): JLN(as-sprayed); (b): JLN(1200 ${ }^{\circ}$, $\left.100 \mathrm{~h}\right)$;

(c): JLN $\left(1300^{\circ} \mathrm{C}, 100 \mathrm{~h}\right) ;(\mathrm{d}): \mathrm{JLN}\left(1400^{\circ} \mathrm{C}, 100 \mathrm{~h}\right) ;(\mathrm{e}): \mathrm{NY} 2$ (as-sprayed);

(f): NY2 $\left(1200^{\circ} \mathrm{C}, 100 \mathrm{~h}\right) ;(\mathrm{g}): \mathrm{NY} 2\left(1300^{\circ} \mathrm{C}, 100 \mathrm{~h}\right) ;(\mathrm{h}): \mathrm{NY} 2\left(1400^{\circ} \mathrm{C}, 100 \mathrm{~h}\right)$

The same phenomenon was presented in Fig.7 with cross-section micrograph of coatings, high temperature sintering caused large pores shrinkage and amount of microspore decreased. Nano scale pores in the nonmolten particles area died out with growth of nano particles, and dense areas caused by fine pores disappeared was increased with annealing temperature. For as-sprayed coatings, porosity of JLN was higher than NY2 owing to the characters of initial spayed powder, dense shell coated loose nano particles conduced JLN coating obtain more strip nonmolten or sintered area(point A in Fig.7), and ensured these nonmolten area did not joint each other with detaching by melted area. Trend of nonmolten particles sintered in the cross-section of coatings identical with nonmolten particles on the surface, particles growth up at high temperature due to some areas densification, especially in NY2 coating, nonmolten particles areas sharply growth caused nano scale pores disappeared. Coating presented excellent capability for pores hold with low impurity content(JLN) at the conditions of $1200^{\circ} \mathrm{C}$ and $1300^{\circ} \mathrm{C}$ annealing, pores with dimension less than $2 \mu \mathrm{m}$ were sharply disappeared after annealing at $1400^{\circ} \mathrm{C}$. Measured the size of nonmolten particles from micrograph of coating surface, the result as shown in Fig.8. Particle size of nonmolten particles of NY2 coating was higher than JLN coating, and growth rate increased with annealing temperature. 


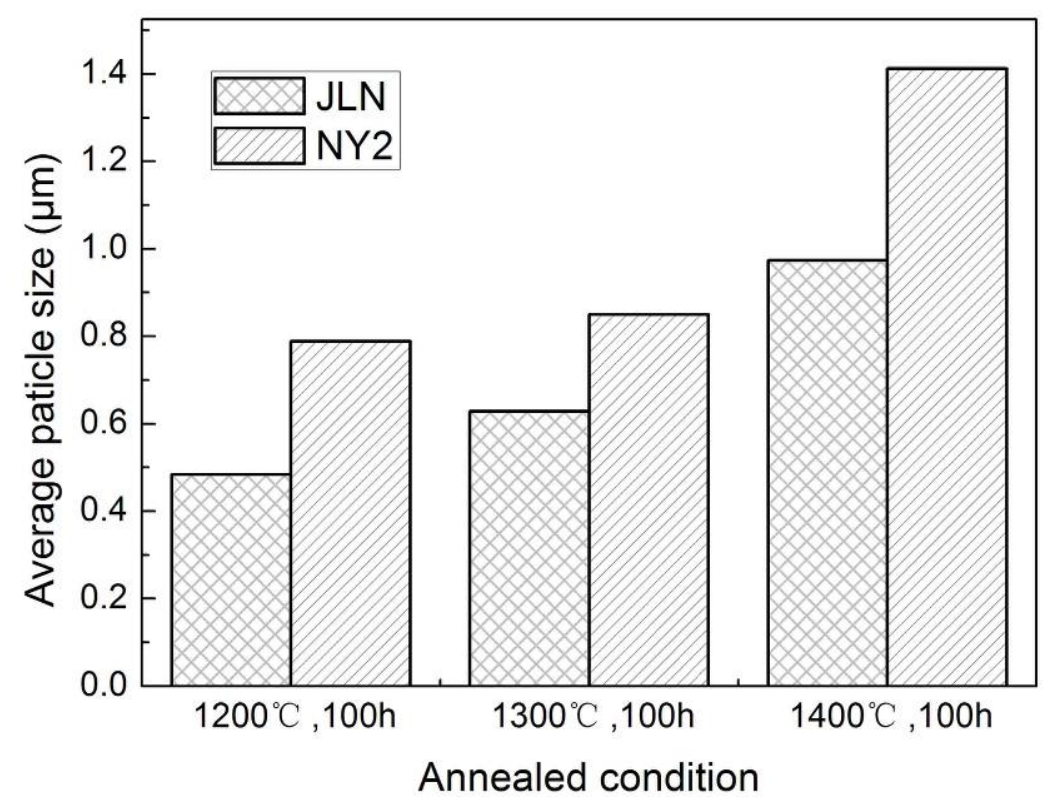

Fig.8 Average particle size of nonmolten particles on the coating surface

These phenomenons upwards illuminated that nanostructure coating maybe lose advantages due to nanostructure and nano size unmolten particles at the condition of exceed normal service temperature, and decreased the impurities content can improve capacity of microstructure retaining at high temperature. On the other hand, unmolten and semi-molten areas also present some pores as shown in Fig.7(b), (c), (f) and (g) after annealing, but size of pores and amount of pores were increased caused by sintering effect.

As-sprayed nanostructure coating possessed nano or superfine scale columnar grains in the lamellar splat of coating, Fig.9(a) and (e) present the fracture micrograph of JLN and NY2 as-sprayed coatings, some columnar grains can distinguish from these FE-SEM images with grain size less than $0.5 \mu \mathrm{m}$. Nano scale and superfine global pores distributed inside the columnar grain and between the gaps of columnar grains, and nomolten particles and semi-molten particles beside the lamellas, some gaps between the lamellas presented a strip shape. Fracture microstructure as shown in Fig.9, thickness of lamella was increased with annealed time, especially for coating after annealed at $1400^{\circ} \mathrm{C}$, thickness of lamella and grain size of columnar grain approached $10 \mu \mathrm{m}, 5 \mu \mathrm{m}$ respectively. Other phenomena as mentioned, fracture morphology presents characteristics with stagger fracture mode of lamella for as-sprayed coating and coatings after annealed $1200^{\circ} \mathrm{C}, 1300^{\circ} \mathrm{C}$, but smooth fracture morphology was obtained with annealing at $1400^{\circ} \mathrm{C}$, it was a clearly fracture mode of sintering and densification zone. Different locations of the fractured coating exhibit similar results.
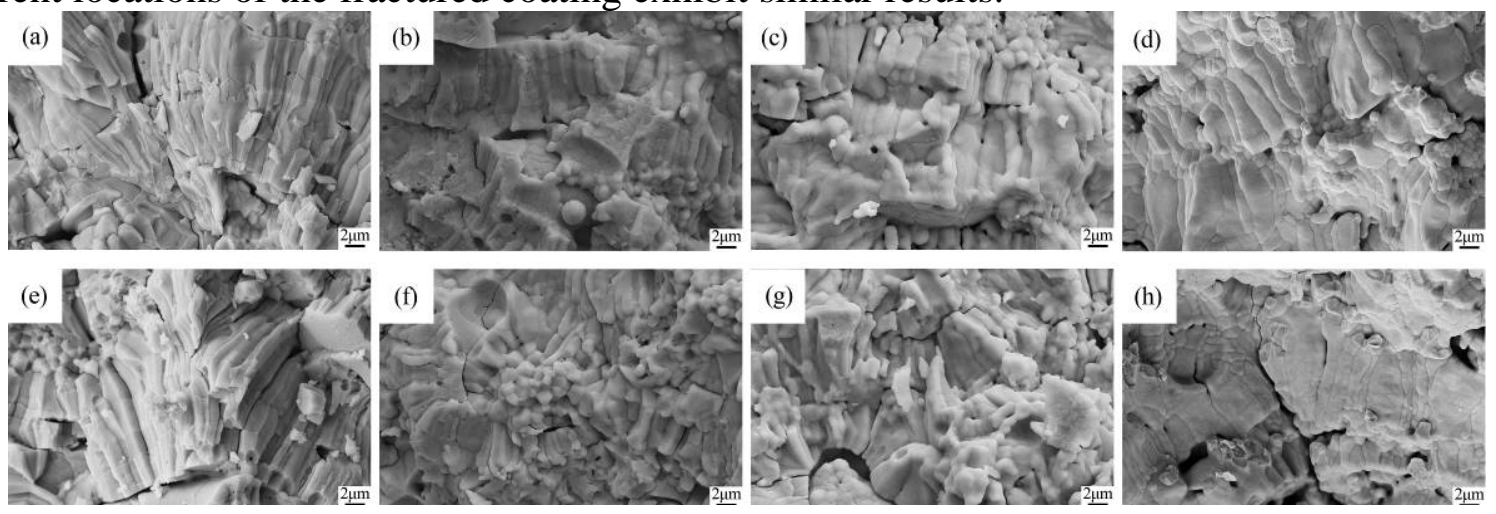

Fig.9 Microstructure of nanostructure 7YSZ coating revealed in this fracture cross-section. (a): JLN(as-sprayed); (b): JLN $\left(1200^{\circ} \mathrm{C}, 100 \mathrm{~h}\right)$; (c): JLN $\left(1300^{\circ} \mathrm{C}, 100 \mathrm{~h}\right)$; (d): JLN $\left(1400^{\circ} \mathrm{C}, 100 \mathrm{~h}\right)$; (e): NY2(as-sprayed); (f): $\mathrm{NY} 2\left(1200^{\circ} \mathrm{C}, 100 \mathrm{~h}\right)$; (g): NY2(1300 $\left.{ }^{\circ} \mathrm{C}, 100 \mathrm{~h}\right) ;(\mathrm{h}): \mathrm{NY} 2\left(1400^{\circ} \mathrm{C}, 100 \mathrm{~h}\right)$ 
HRTEM microstructure of JLN as-sprayed coating and after annealing $100 \mathrm{~h}$ at $1400^{\circ} \mathrm{C}$ is shown in Fig.10, it present that grain size of some columnar grains less than 50nm. Impurities segregate in grain boundary and distortion of lattice are not obvious as shown in Fig.10(b).
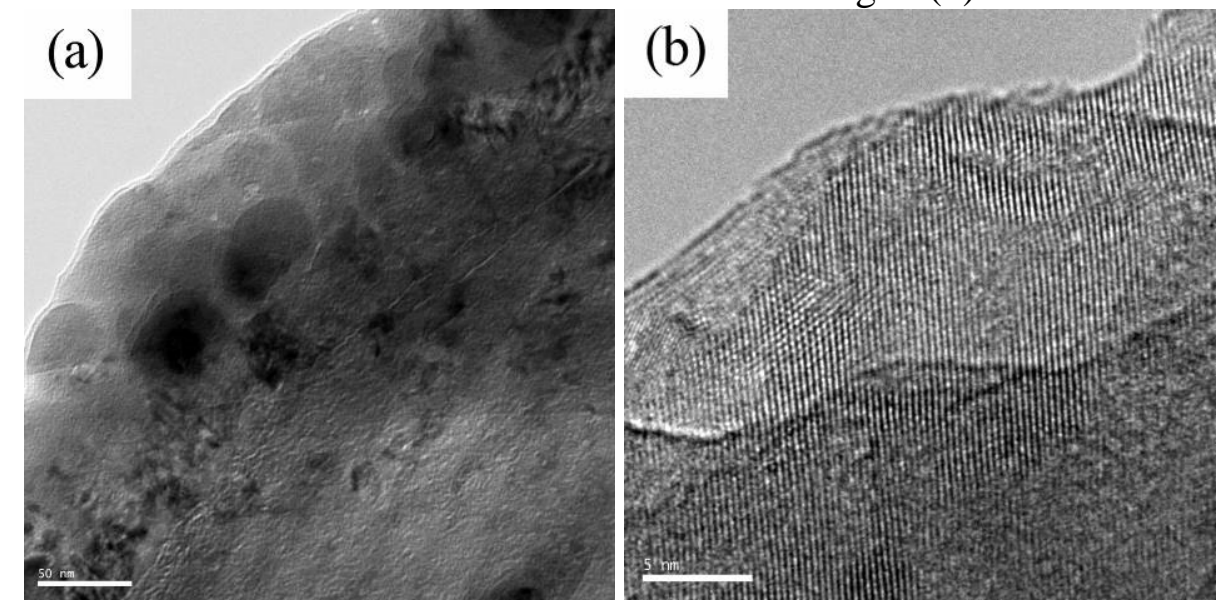

Fig.10 HRTEM image of as-sprayed JLN coating.

(a): as-sprayed; (b) lattice image of JLN coating after annealed $100 \mathrm{~h}$ at $1400^{\circ} \mathrm{C}$

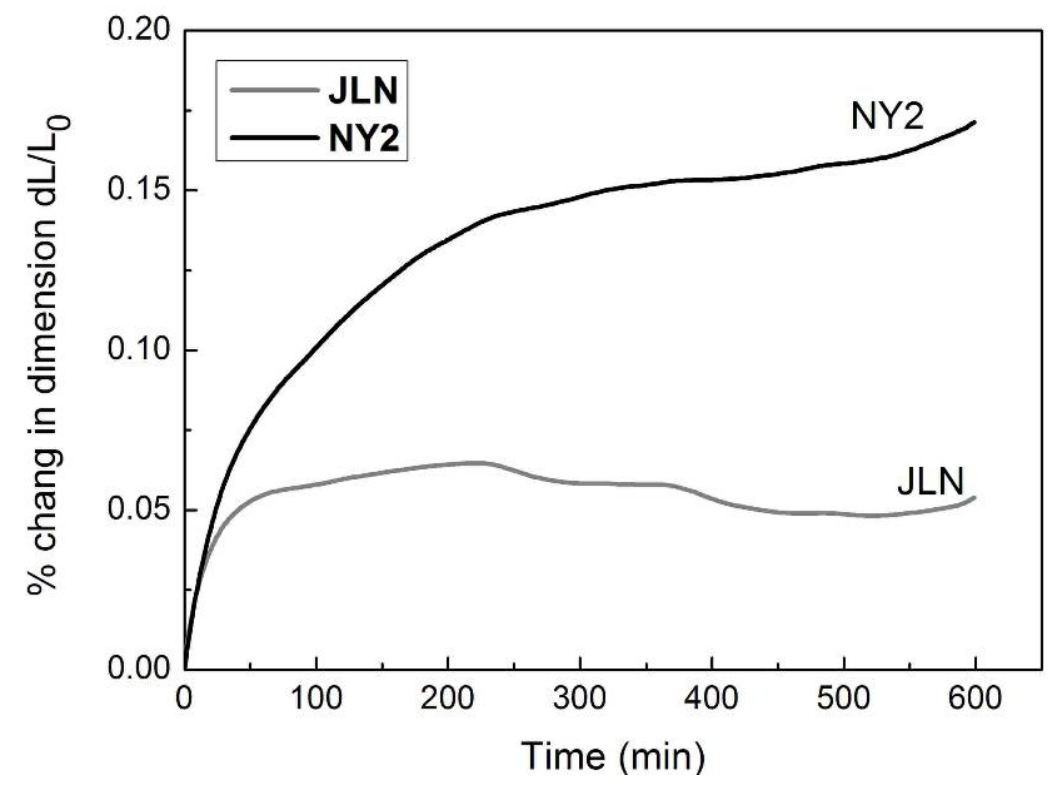

Fig.11 Through-thickness shrinkage behavior at $1260^{\circ} \mathrm{C}$

For directly obtained the shrinkage caused by high temperature sintering, dimensional changes through coating thickness at $1260^{\circ} \mathrm{C}$ as shown in Fig. 11 . At the beginning time of heat preservation period, two coatings presented large shrinkage caused by sustaining dilatability at the heating-up process. After this period, NY2 coating exhibited continuity shrinkage until end of heat preservation period, but dimensional changes through coating thickness of JLN coating was very imperceptibility. During heat preservation period, amount quantity of coating shrinkage was $0.17 \%$ for NY2 coating and $0.05 \%$ for JLN coating. Coating shrunk at the heat preservation period due to grain growth up and pores, cracks cicatrized, also relate to the porosity of as-sprayed coating. Contrast the result of dimensional changes through coating thickness show that low impurities content maybe an effective way to increase the ability of sinter resistance for nanostructured coating, and microstructure design for initial sprayed powder also a possible effect factor. 


\section{Conclusion}

In summary it has been found nanostructured coating exhibit excellent capability of microstructure retention at differential sintering, sintering effects caused large pores shrinkage, lamella incrassation, columnar grain growth up and surface layer stripping. Unmolten and semi-molten areas contribute microstructure retention due to high driving fore and nano scale pores combined for nanozones. Shrinking rate of some large pores and desen area are increased with increasing annealing temperature, grain and unmolten particle growth up rate are also increased with increasing annealing temperature but the rates of JLN coating with low impurity is lower than NY2 coating. Impurity content in initial sprayed 7YSZ powder obviously effects on high temperature phase stability of powder and coating, JLN spayed material and coating exhibit more excellent ability for tetragonal prime $t$ ' phase retained during different annealing time at $1400^{\circ} \mathrm{C}$. Dimensional changes through coating thickness directly represent that JLN coating from microstructure modified and low impurity content powder exhibit more excellent high temperature sinter resistance than NY2 coating, and microstructure evolved during annealing at different conditions also support this result.

\section{References}

[1] G.W. Goward. Progress in coatings for gas turbine airfoils. Surface and Coatings Technology, 1998, 108-109: 73-79

[2] Nitin P. Padture, Maurice Gell, Eric H. Jordan. Thermal Barrier Coatings for Gas-Turbine Engine Applications. Science, 2002, 296: 280-284

[3] S. M. Meier, D. K. Gupta. The Evolution of Thermal Barrier Coatings in Gas Turbine Engine Applications. Journal of Engineering for Gas Turbines and Power, 1994, 116: 251-257

[4] S. Stecura. Effects of Compositional Changes on the Performance of a Thermal Barrier Coating System. NASA TM-78976, National Aeronautics and Space Administration, 1978

[5] A. Cipitria, I.O. Golosnoy, T.W. Clyne. Sintering Kinetics of Plasma-Sprayed Zirconia TBCs. Journal of Thermal Spray Technology, 2007, 16(5-6): 809-815

[6] W. Ma, S.K. Gong, H.B. Xu, X.Q. Cao, Surf. Coat. Technol. 200 (2006) 5113-5118

[7] Huaifei Liu, Songlin Li, Qilian Li, Yongming Li, Wuxi Zhou. Microstructure, phase stability and thermal conductivity of plasma sprayed $\mathrm{Yb} 2 \mathrm{O} 3$, Y2O3 co-stabilized $\mathrm{ZrO} 2$ coatings. Solid State Sciences, 2011, 13: 513-519

[8] S. Paul, A. Cipitria, I.O. Golosnoy, L. Xie, M.R. Dorfman, T.W. Clyne. Effects of Impurity Content on the Sintering Characteristics of Plasma-Sprayed Zirconia. Journal of Thermal Spray Technology, 2007, 16(5-6): 798-803

[9] Carlos G. Levi. Emerging materials and processes for thermal barrier systems. Current Opinion in Solid State and Materials Science, 2004, 8: 77-91

[10] Robert Vassen, Alexandra Stuke, Detlev Stöver. Recent Developments in the Field of Thermal Barrier Coatings. Journal of Thermal Spray Technology, 2009, 18(2): 181-186

[11] Dongming Zhu, Yuan L. Chen, Robert A. Miller. Defect Clustering and Nano-phase Structure Characterization of Multicomponent Rare-Earth Oxide Doped Zirconia-Yttria Thermal Barrier Coatings. Ceramic Eng. Sci. Proc., 2003, 24:

[12] R. C. Garvie and M. F. Goss: J. Mater. Sci., 21, 1986

[13] H. Tsubakino, T. Fujiwara, K. Satani and S. Ioku: J. Mater. Sci. Lett., 1997, 16, 1472-1475 
[14] Grégoire Witz, Valery Shklover, Walter Steurer. Phase Evolution in Yttria-Stabilized Zirconia Thermal Barrier Coatings Studied by Rietveld Refinement of X-Ray Powder Diffraction Patterns. J. Am. Ceram. Soc. 1-6 (2007)

[15] Chungen Zhou, Na Wang, Huibin Xu. Comparison of thermal cycling behavior of plasma-sprayed nanostructured and traditional thermal barrier coatings. Materials Science and Engineering A, 452-453 (2007) 569-574

[16] W. Q. Wang, C. K. Sha, D. Q. Sun, X. Y. Gu, Microstructural Feature, Thermal Shock Resistance and Isothermal Oxidation Resistance of Nanostructured Zirconia Coating, Materials Science and Engineering A, 424 (2006) 1-5

[17] B. Liang, C. Ding, Thermal Shock Resistances of Nanostructured and Conventional Zirconia Coatings Deposited by Atmospheric Plasma Spraying, Surface and Coatings Technology, 197 (2005) 185-192

[18] R. S. Lima, A. Kucuk, C. C. Berndt, Bimodal Distribution of Mechanical Properties on Plasma Sprayed Nanostructured Partially Stabilized Zirconia, Materials Science and Engineering A, 327 (2002) 224-232.

[19] R.S. Lima, B.R. Marple. Nanostructured YSZ Thermal Barrier Coatings Engineered to Counteract Sintering Effects. Materials Science and Engineering A, 2007

[20] B. Basu. Toughening of yttria-stabilised tetragonal zirconia ceramics. International Materials Reviews, 2005, VOL 50: 239-256

[21] Harry E. Eaton, Paul Zajchowski. High temperature particulate erosion of plasma sprayed YSZ versus selected powder characteristics and plasma torch designs. Surface and Coatings Technology, 120-121 (1999) 28-33

[22] R. G Wellman, J. R. Nicholls. A Review of the Erosion of Thermal Barrier Coatings. Journal of Physics D: Applied Physics, 2007, 40, No. 16, R293-R305

[23] R.A. Miller, J.L. Smialek, and R.G. Garlick: "Phase Stability in Plasma-Sprayed, Partially Stabilized Zirconia-Yttria" in Advances in Ceramics, Vol. 3: Science and Technology of Zirconia, A.H. Heuer and L.W. Hobbs, ed., The American Ceramics Society, Columbus, OH, 1982, pp. 241-53 